\title{
Cementitious Spray Dryer Ash-Tire Fiber Material for Maximizing Waste Diversion
}

\author{
Charles E. Riley, ${ }^{1}$ Rebecca A. Atadero, ${ }^{2}$ John W. van de Lindt, ${ }^{3}$ and Paul R. Heyliger ${ }^{2}$ \\ ${ }^{1}$ Department of Civil Engineering, Oregon Institute of Technology, 3201 Campus Drive, Klamath Falls, OR 97601, USA \\ ${ }^{2}$ Department of Civil and Environmental Engineering, Colorado State University, Campus Delivery 1372, Fort Collins, \\ CO 80523-1372, USA \\ ${ }^{3}$ Department of Civil, Construction, and Environmental Engineering, University of Alabama, Tuscaloosa, AL 35487-0205, USA
}

Correspondence should be addressed to Rebecca A. Atadero, ratadero@engr.colostate.edu

Received 31 December 2010; Accepted 17 May 2011

Academic Editor: Paola Bandini

Copyright (๑) 2011 Charles E. Riley et al. This is an open access article distributed under the Creative Commons Attribution License, which permits unrestricted use, distribution, and reproduction in any medium, provided the original work is properly cited.

\begin{abstract}
Spray dryer absorber (SDA) material, also known as spray dryer ash, is a byproduct of coal combustion and flue gas scrubbing processes that has self-cementing properties similar to those of class $\mathrm{C}$ fly ash. SDA material does not usually meet the existing standards for use as a pozzolan in Portland cement concrete due to its characteristically high sulfur content, and thus unlike fly ash, it is rarely put to beneficial use. This paper presents the results of a study with the objective of developing beneficial uses for SDA material in building materials when combined with tire fiber reinforcement originating from a recycling process. Specifically, spray dryer ash was investigated for use as the primary or even the sole binding component in a mortar or concrete. This study differs from previous research in that it focuses on very high contents of spray dryer ash ( 80 to 100 percent) in a hardened product. The overarching objective is to divert products that are normally sent to landfills and provide benefit to society in beneficial applications.
\end{abstract}

\section{Introduction}

Portland cement concretes and mortars are used extensively in construction of buildings, bridges, and other infrastructure ranging from low-strength sidewalks to highperformance airport runways. Despite recent advances in manufacture, Portland cement remains an energy-intensive product that requires mining of raw materials as well as significant energy input and processing. Incorporation of coal fly ash into concrete mixtures is now widely accepted given its capacity to produce an equivalent or even improved hardened concrete product with less Portland cement and, therefore, reduced raw materials extraction and carbon emissions [1]. However, a substantial portion of fly ash produced each year goes unused, and a significant portion of the country's ash material is deemed useless because it is involved in the flue gas desulfurization process within the spray dryer absorbers utilized at many of the United States coal power plants [2]. It is the material from this subset of plants, alternatively called spray dryer absorber material, SDA material, or spray dryer ash, that is the subject of this research.
Spray dryer ash is produced in far smaller quantities than fly ash in the US. The American Coal Ash Association, ACCA, estimates 1.4 million tons for all dry flue gas desulfurization products, of which spray dryer ash makes up a large portion [3]. While nearly 42 percent of all fly ash produced in the United States (approximately 72 million tons annually [3]) is used beneficially, only about 25 percent of dry FGD products was used in 2008 [3]. Furthermore, the Electric Power Research Institute (EPRI) [2] estimates much higher annual production rates for SDA material than does ACAA: between 3.3 and 3.8 million tons, with that number projected to grow to 14 million tons by 2017 as more plants are required to reduce airborne sulfur emissions. Thus, the need for more beneficial applications of this material is critical.

While fly ash use and performance in concrete has been well documented [1], the mechanical properties of hydrated SDA material have not been studied adequately, in part due to concerns that the elevated sulfur levels will lead to sulfate attack in the hardened product [2]. A recent literature review by EPRI [2] surveyed the current uses for SDA and found applications ranging from agriculture to cementitious 
TABLE 1: Bulk chemical composition of rawhide power station SDA.

\begin{tabular}{|c|c|c|c|c|c|}
\hline Compound & $\begin{array}{c}\text { Sample } 1 \\
\text { Content A (\%) }\end{array}$ & $\begin{array}{c}\text { Sample } 2 \\
\text { Content B (\%) }\end{array}$ & $\begin{array}{c}\text { Sample } 3 \text { Content C } \\
(\%)\end{array}$ & $\begin{array}{l}\text { ASTM C618 limit for } \\
\text { Class C fly ash (2005) }\end{array}$ & $\begin{array}{c}\text { ASTM C } 618 \text { limit for class } \\
\text { F fly ash (2005) }\end{array}$ \\
\hline Silicon dioxide, $\mathrm{SiO}_{2}$ & 39.76 & 29.84 & & $\begin{array}{c}\text { Sum between } 50 \% \text { and } \\
70 \%\end{array}$ & Sum greater than $70 \%$ \\
\hline $\begin{array}{l}\text { Aluminum oxide, } \\
\mathrm{Al}_{2} \mathrm{O}_{3}\end{array}$ & 14.31 & 14.24 & & & \\
\hline Iron oxide, $\mathrm{Fe}_{2} \mathrm{O}_{3}$ & 5.56 & 5.82 & & & \\
\hline $\mathrm{SiO}_{2}+\mathrm{Al}_{2} \mathrm{O}_{3}+\mathrm{Fe}_{2} \mathrm{O}_{3}$ & 59.63 & 49.90 & 60.63 & & \\
\hline Calcium oxide, $\mathrm{CaO}$ & 23.45 & 26.48 & & & \\
\hline Sulfur trioxide, $\mathrm{SO}_{3}$ & 6.19 & 10.01 & 3.70 & $5 \%$ maximum & $5 \%$ maximum \\
\hline $\begin{array}{l}\text { Magnesium oxide, } \\
\mathrm{MgO}\end{array}$ & 4.06 & 4.93 & & & \\
\hline Sodium oxide, $\mathrm{Na}_{2} \mathrm{O}$ & 1.42 & 1.66 & & & \\
\hline $\begin{array}{l}\text { Titanium dioxide, } \\
\mathrm{TiO}_{2}\end{array}$ & 1.15 & 0.98 & & & \\
\hline $\begin{array}{l}\text { Phosphorous } \\
\text { pentoxide, } \mathrm{P}_{2} \mathrm{O}_{5}\end{array}$ & 0.98 & 1.59 & & & \\
\hline Barium oxide, $\mathrm{BaO}$ & 0.61 & 0.68 & & & \\
\hline Potassium oxide, $\mathrm{K}_{2} \mathrm{O}$ & 0.53 & 0.48 & & & \\
\hline Strontium oxide, $\mathrm{SrO}$ & 0.33 & 0.42 & & & \\
\hline $\begin{array}{l}\text { Manganese dioxide, } \\
\mathrm{MnO}_{2}\end{array}$ & $<0.01$ & 0.02 & & & \\
\hline Moisture & 1.86 & 1.04 & 1.33 & $3 \%$ maximum & $3 \%$ maximum \\
\hline Loss on ignition & 1.65 & 2.85 & 1.64 & $6 \%$ maximum & $6 \%$ maximum \\
\hline
\end{tabular}

A: sampled 4/3/2007 and tested by SGS North America, Inc., Denver, Colo, USA.

B: sampled 7/26/2007 and tested by Wyoming Analytical Laboratories, Inc., Golden, Colo, USA.

C: reported in Little, 2008 [10].

materials to wallboard; however, most of the applications noted in this paper were found in Europe where the composition of SDA is different from that produced at the US electric power plants. In European processes, the fly ash and spray dryer product are collected separately. The fact that US sources combine the fly ash and spray dryer product means not only that the resulting material is more variable, but also that the beneficial properties of the fly ash can be exploited.

The project described here seeks to leverage the selfcementing nature of this material to create a cementitious product with as little Portland cement as possible. Thus, the emphasis of this work is not on achieving the highest possible strength, but in diverting as much waste material as possible into a useful product that maintains adequate properties. In the present study, applications with lower strength requirements (e.g., nonstructural components) are targeted with the cemented SDA combined with fibers collected during the automobile tire recycling process as reinforcement. The results indicate that good compressive and tensile strength is possible. While these results are for a specific SDA material source, they suggest that useful materials may be produced with this presently underutilized industrial byproduct. They also indicate the value of further study of SDA material sources and long-term material performance.

\section{Materials and Specimens}

Two different types of materials were studied. The first was a material comprised solely of spray dryer ash and water, with some specimens also including recycled polymer fibers from used automobile tires (described in more detail below). Second, mortar specimens manufactured with spray dryer ash, sand conforming to ASTM C33 [4], varied amounts of Portland cement, and recycled polymer fibers were considered.

Table 1 shows details of the chemical composition of three samples of the SDA material produced by the Rawhide power plant in Northern Colorado. The quantities in Table 1 indicate the level of variability present in SDA material from just a single source, thus underscoring a need for site-specific study to ensure the quality control of SDA material as an input. Of particular note is the very high lime content (over 
TABLE 2: Mixture proportions.

\begin{tabular}{|c|c|c|c|c|c|c|}
\hline Mixture number & Cement type & Cement $^{a}$ & $\mathrm{SDA}^{\mathrm{a}}$ & Sand $^{a}$ & Water $^{a}$ & Fibers $^{\mathrm{b}}$ \\
\hline $1 \mathrm{~A}$ & - & 0 & 100 & 0 & 40 & 0 \\
\hline $1 \mathrm{~B}$ & - & 0 & 100 & 0 & 35 & 0 \\
\hline $1 \mathrm{C}$ & - & 0 & 100 & 0 & 30 & 0 \\
\hline 1D & - & 0 & 100 & 0 & 25 & 0 \\
\hline $1 \mathrm{E}$ & - & 0 & 100 & 0 & 25 & 0.5 \\
\hline $1 \mathrm{~F}$ & - & 0 & 100 & 0 & 25 & 1.0 \\
\hline $1 \mathrm{G}$ & - & 0 & 100 & 0 & 25 & 2.0 \\
\hline $2 \mathrm{~A}$ & - & 0 & 100 & 100 & 40 & 0 \\
\hline $2 \mathrm{~B}$ & III & 5 & 95 & 100 & 40 & 0 \\
\hline $2 \mathrm{C}$ & III & 10 & 90 & 100 & 40 & 0 \\
\hline $2 \mathrm{D}$ & III & 15 & 85 & 100 & 40 & 0 \\
\hline $2 \mathrm{E}$ & III & 20 & 80 & 100 & 40 & 0 \\
\hline $2 \mathrm{~F}$ & I/II & 5 & 95 & 100 & 40 & 0 \\
\hline $2 \mathrm{G}$ & $\mathrm{I} / \mathrm{II}$ & 10 & 90 & 100 & 40 & 0 \\
\hline $2 \mathrm{H}$ & $\mathrm{I} / \mathrm{II}$ & 15 & 84 & 100 & 40 & 0 \\
\hline $2 \mathrm{I}$ & $\mathrm{I} / \mathrm{II}$ & 20 & 80 & 100 & 40 & 0 \\
\hline $2 \mathrm{~J}$ & $\mathrm{I} / \mathrm{II}$ & 10 & 90 & 100 & 40 & 1.0 \\
\hline $2 \mathrm{~K}$ & $\mathrm{I} / \mathrm{II}$ & 10 & 90 & 100 & 40 & 1.5 \\
\hline $2 \mathrm{~L}$ & $\mathrm{I} / \mathrm{II}$ & 10 & 90 & 100 & 40 & 2.0 \\
\hline
\end{tabular}

${ }^{\mathrm{a}}$ These quantities are expressed as a percent by weight relative to the total weight of SDA and cement in the mixture.

${ }^{b}$ Expressed as a percent by weight of the total solids (SDA, cement and sand) in the mixture.

20 percent $\mathrm{CaO}$ ), which contributes to the self-cementing capacity of the material. The $\mathrm{SO}_{3}$ content, which is typically slightly in excess of the 5 percent limit for fly ash used in concrete as specified by ASTM C618 [5], is also notable. This excess sulfur has prevented the application of the material in concrete to date, but because the amount of excess is still quite modest, the material merits individual study.

The polymer fibers used in this study were obtained from an automobile tire recycling facility and represented a combination of polymers commonly used as tire reinforcement such as nylon, polyester, and aramid with lengths randomly distributed between approximately $2 \mathrm{~mm}$ and $30 \mathrm{~mm}$. The steel wires present in most automotive tires were removed magnetically at early stages of the recycling process. The polymer fibers were interspersed with rubber particles varying from fine dust to larger pieces less than $5 \mathrm{~mm}$ in dimension as well as raw chopped fibers that were still twisted together in cords. These recycled fibers were chosen for their compatibility with the theme of waste diversion and sustainable construction, which is a prime motivator for developing a cementitious material with industrial byproducts. Because of variability in fiber size and constitution, all fiber fractions are by weight, as without the density it was not possible to determine a volume fraction. However, given the range of specific gravities of the potential reinforcing fibers, a volume fraction very nearly equal to the weight fraction is reasonable.

The mixture proportions of the specimens are shown in Table 2. Mixtures numbered 1 are spray dryer ash pastes, while those numbered 2 are spray dryer ash-based mortars. Sets $1 \mathrm{~A}$ through 1D were composed solely of spray dryer ash and water and were intended to study the effect of waterto-ash ratio on the compressive strength of the hardened paste. Sets $1 \mathrm{E}$ through $1 \mathrm{G}$ included varying percentages of the recycled polymer fibers, in order to investigate their effect on the hydrated ash pastes.

The mortar mixtures had a constant water/cementitious materials ratio of 0.40 but had varying amounts of Portland cement and recycled polymer fibers in an effort to improve on the properties observed in the spray dryer ash pastes. Two types of Portland cement were used. Type I/II was used because it is very commonly available. Type III cement was also used because in the case of fly ash, there is usually a reduced rate of strength gain when mixtures including fly ash are compared to mixtures with just Portland cement, and it was anticipated that the same situation might occur with spray dryer ash. Research by Bilodeau and Malhotra [6] indicated the high early strength properties of Type III cement would bring the strength versus time characteristics of the hydrated ash (Class F fly ash in the case of Bilodeau and Malhotra) closer to those of conventional concrete. This is important for construction scheduling for structural applications and shipping/trucking scheduling for nonstructural construction materials such as siding or roof tiles.

The compressive strengths of the mixtures in Table 2 were investigated using $5.08-\mathrm{cm}$ cubes following the dimensions suggested in ASTM C109 [7]. Mortar testing also included flexural specimens: beams with approximate dimensions $5.08 \mathrm{~cm}$ by $5.08 \mathrm{~cm}$ by $20.3 \mathrm{~cm}$ tested according to ASTM C78 [8] with a $15.2-\mathrm{cm}$ clear span.

For both pastes and mortars, the constituent materials were mixed approximately according to ASTM C 305 [9] to ensure uniformity of the mixtures, which was particularly important for the paste mixtures with a low water/ash ratio. 


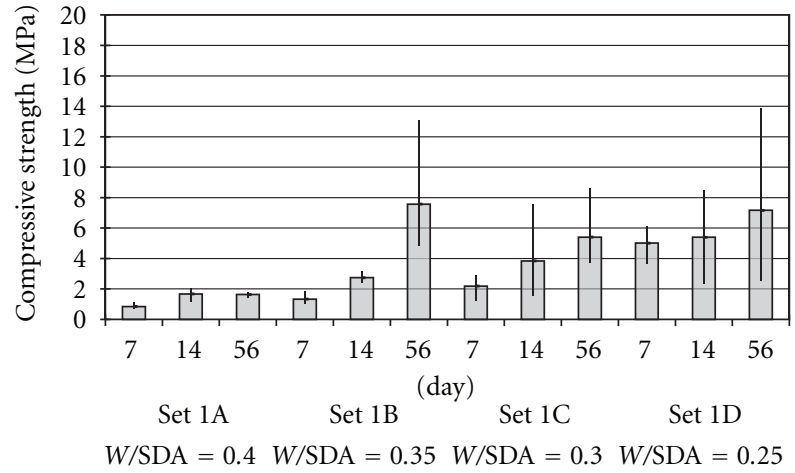

FIGURE 1: Early compressive strength of hydrated spray dryer ash pastes.

The sole deviation from ASTM C 305 was the mixing device. A mixing bit and hand drill were used in lieu of a planetary rotary mixer. Paste specimens were cured at approximately 80 percent humidity and between 26 and 32 degrees $C$ (7990 degrees $\mathrm{F}$ ). This slightly elevated temperature was meant to accelerate curing, as would be found at a manufacturing plant for a prefabricated building material. The mortar specimens were placed in a more traditional curing room that maintained a relative humidity of approximately 90 percent and a temperature of approximately 22 degrees $\mathrm{C}$ (72 degrees F). For both pastes and mortars, the specimens were placed in the curing environment directly after casting and were returned to the curing environment following removal of the molds after approximately one day. Paste tests were conducted at seven-day intervals, with five cubes tested from each mixture. For the mortars, three cubes were tested at seven-day intervals up to 28 days, while three beams were tested at 14 and 28 days for each of the nine mixtures.

\section{Discussion}

3.1. Hydrated Spray Dryer Ash Pastes. Recall that the objective of this study was to divert as much spray dryer ash as possible from landfilling. Thus, the first experiments evaluated the potential of hydrated spray dryer ash alone in manufactured structural and nonstructural construction products. Early strength gain is an important item of consideration for these materials because manufacturers of commercial products require shipment as quickly as possible, often in as little as seven days. Figure 1 shows the results of 7 , 14, and 56 day tests for Sets 1A through 1D. These sets were composed of spray dryer ash pastes with water/ash ratios ranging from 0.40 for Set $1 \mathrm{~A}$ to 0.25 for Set 1D. Figure 1 shows the average strength as well as the high and low values. Although the compressive strengths showed considerable variability, in general, there is an increase in compressive strength that is inversely linear with water/ash ratio.

Figure 2 shows the results for compressive strength for Sets $1 \mathrm{D}$ through $1 \mathrm{G}$ with high, low, and average strengths included. These sets all had a fixed water/ash ratio of 0.25 and demonstrate the effect of inclusion of the polymer fibers derived from tire recycling. Set $1 \mathrm{D}$ had no fibers, while Sets

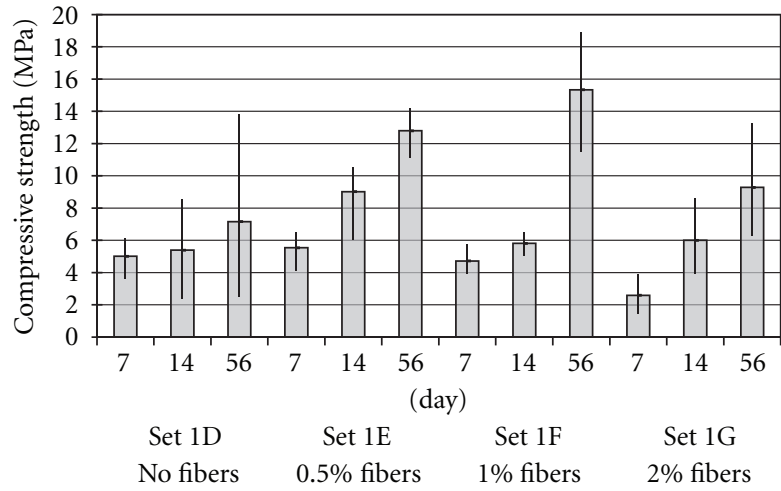

FIGURE 2: Early compressive strength of hydrated spray dryer ash with fibers.

TABLE 3: Average 56-day compressive strength and modulus of elasticity measured from cube specimens.

\begin{tabular}{lcc}
\hline Set & $\begin{array}{c}\text { Average 56-day } \\
\text { compressive strength } \\
(\mathrm{MPa})\end{array}$ & $\begin{array}{c}\text { Average 56-day modulus } \\
\text { of elasticity (MPa) }\end{array}$ \\
\hline $1 \mathrm{~A}$ & 1.63 & 119.6 \\
$1 \mathrm{~B}$ & 7.57 & 408.4 \\
$1 \mathrm{C}$ & 5.40 & 382.8 \\
$1 \mathrm{D}$ & 7.16 & 376.9 \\
$1 \mathrm{E}$ & 12.79 & 565.9 \\
$1 \mathrm{~F}$ & 15.34 & 557.2 \\
$1 \mathrm{G}$ & 9.28 & 395.5 \\
\hline
\end{tabular}

$1 \mathrm{E}, 1 \mathrm{~F}$, and $1 \mathrm{G}$ had increasing fiber fractions as shown in Table 2. Based on the results shown in Figure 2, the fiber reinforcement appears to be beneficial to the compressive strength with an optimum fiber fraction around 1 percent. Set $1 \mathrm{E}$ with 0.5 percent fibers (recall, by weight) shows a clear increase in strength over Set 1D with no fibers. It appears that the addition of more fibers (Set $1 \mathrm{~F}$ with 1 percent and Set $1 \mathrm{G}$ with 2 percent) has little impact on the strength, or may even weaken the mixture slightly, perhaps due to greater difficulty in creating a uniform mix. The increase in strength may be attributed to the ability of the fibers to bridge cracks and act as reinforcement in a relatively weak and brittle matrix material. The pictures shown in Figure 3 are examples of the appearance of typical cubes with and without fibers after testing to failure. In general, cubes without fibers fractured into numerous pieces, while cubes with fibers showed cracking and deformation but maintained their general shape even after the initial cracking and the associated significant reduction in capacity. The inclusion of a small amount of fibers leads to a significant (20 to 70 percent) increase in compressive strength, but this increase appears to peak at fairly low fiber weight fractions.

The ultimate compressive strength of hydrated spray dryer ash will depend on the specific chemical composition of the ash and the long-term curing conditions. However, it is of interest to know approximate values for the compressive strength for both neat and fiber-reinforced spray dryer ash. 
TABLE 4: Compressive strength for different types of cement, testing ages and percents of cement added (MPa).

\begin{tabular}{|c|c|c|c|c|c|c|c|c|c|}
\hline \multirow[b]{2}{*}{ Days } & \multirow[b]{2}{*}{$0 \%$} & \multicolumn{4}{|c|}{ Type I cement (Sets 2F-2I) } & \multicolumn{4}{|c|}{ Type III cement (Sets 2B-2E) } \\
\hline & & $5 \%$ & $10 \%$ & $15 \%$ & $20 \%$ & $5 \%$ & $10 \%$ & $15 \%$ & $20 \%$ \\
\hline 7 & 4.09 & 17.62 & 13.03 & 16.19 & 15.88 & 15.18 & 23.00 & 19.85 & 23.04 \\
\hline 14 & 6.91 & 23.61 & 17.83 & 23.92 & 25.70 & 20.65 & 27.09 & 27.82 & 24.37 \\
\hline 21 & 8.03 & 24.43 & 24.53 & 32.64 & 32.84 & 23.64 & 29.98 & 27.06 & 31.91 \\
\hline 28 & 7.99 & 27.37 & 27.15 & 34.00 & 37.18 & 22.87 & 29.26 & 29.23 & 28.79 \\
\hline
\end{tabular}

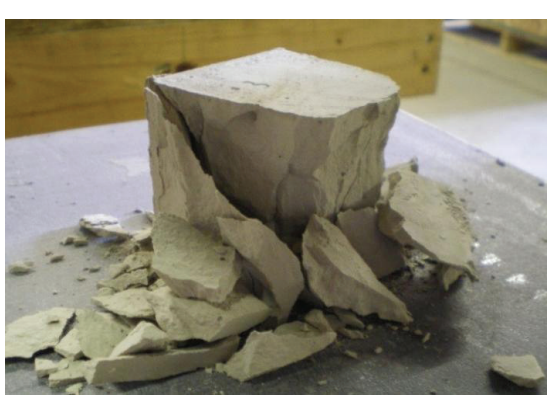

(a)

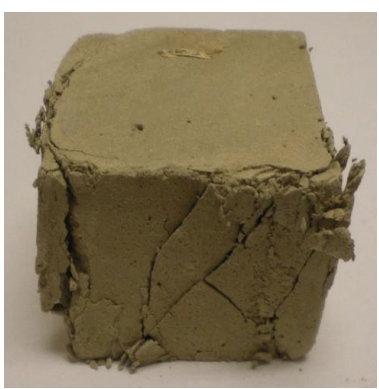

(b)

Figure 3: Typical cube appearance after compressive testing without (a) and with (b) polymer fibers.

Table 3 shows the average 56-day compressive strengths and moduli achieved. The modulus of elasticity was calculated from the cube tests using a linear fit to initial portions of the stress-strain curve, and the strain was calculated from the test machine crosshead displacement data collected during the compressive strength tests. For the most part, the trends witnessed in the early strengths are continued at later strengths: decreasing the water/ash ratio results in an increase in strength, and modest use of tire fiber (about 1 percent) yields additional increase that declines with the addition of more fibers.

The highest average strengths observed for the hydrated spray dryer ash with and without fibers were $15.3 \mathrm{MPa}$ and 7.5 MPa, respectively. These strengths were achieved at an age of 56 days and indicate that hydrated spray dryer ash alone is not likely to be suitable for many structural engineering uses. Aesthetically, the finished cubes had limited resistance to scratching or abrasion and for high water ratios especially, seemed to have a chalky finish. The material was also observed to readily absorb water. A cube dipped in water appeared dry in less than one minute because the water had

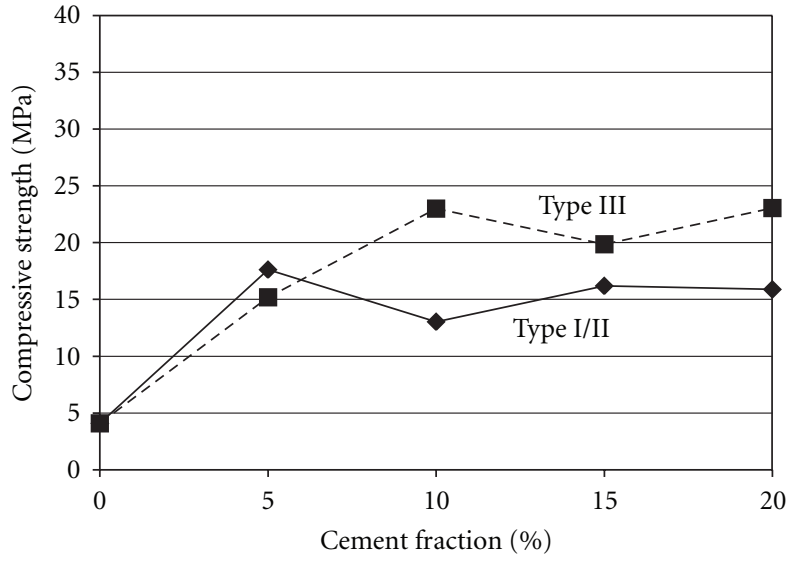

Figure 4: Comparison of compressive strength at 7 days for mixtures with type I/II and type III cement.

been absorbed into the cube. Based on these results, the mortar mixtures were developed and tested to study potential means of achieving enhanced properties while still utilizing large quantities of spray dryer ash.

3.2. Hydrated Spray Dryer Ash Sanded Mortars. Seeking to improve the properties of the spray dryer ash pastes, the researchers considered the addition of sand and small amounts of Portland cement. To maximize spray dryer ash usage, cement quantities of only five, ten, fifteen, and twenty percent were considered. This can be thought of as the inverse of typical fly ash applications, where smaller amounts of fly ash are used as additives to traditional concrete mixtures. As indicated earlier, both Type I/II and Type III cements were tested.

Table 4 summarizes the results of testing at 7, 14, 21, and 28 days for specimens with varied cement fraction. From this table, it is immediately obvious that the addition of even five percent Portland cement (of either type) has a significant impact on the compressive strength. At 28 days, including five percent of Type I/II cement in the mixture increased the compressive strength over the mixture with just spray dryer ash binder by about 3.4 times, from 8.0 to 27.4 MPa, and the Type III cement increased the compressive strength by nearly 2.7 times, from 8.0 to $22.9 \mathrm{MPa}$. Figures 4 and 5 compare the effect of the different types of cement at ages of 7 and 28 days, respectively. Figure 4 shows that Type III cement outperformed Type I/II cement at the early age of 7 days, as would be expected from cement 
TABLE 5: Modulus of elasticity for different types of cement, testing ages and percents of cement added (MPa).

\begin{tabular}{lccccccccc}
\hline & & \multicolumn{3}{c}{ Type I cement (Sets 2F-2I) } & \multicolumn{4}{c}{ Type III cement (Sets 2B-2E) } \\
Days & $0 \%$ & $5 \%$ & $10 \%$ & $15 \%$ & $20 \%$ & $5 \%$ & $10 \%$ & $15 \%$ & $20 \%$ \\
\hline 7 & 686 & 2022 & 1666 & 1965 & 1720 & 1609 & 2354 & 2193 & 2474 \\
14 & 1080 & 2681 & 2176 & 2337 & 2099 & 2513 & 2612 & 2643 & 2938 \\
21 & 1051 & 2773 & 2612 & 3208 & 3122 & 2428 & 2648 & 2911 & 2819 \\
28 & 881 & 2850 & 3172 & 3360 & 2869 & & &
\end{tabular}

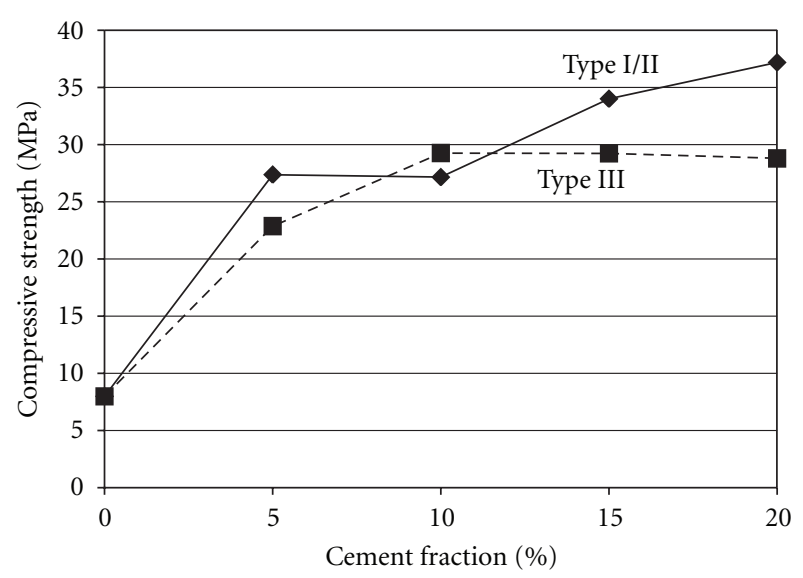

Figure 5: Comparison of compressive strength at 28 days for mixtures with type I/II and type III cement.

formulated to give high early strengths. However, Figure 5 shows that the long-term strength was generally higher with the addition of Type I/II cement. These figures also show that the increase in strength with the addition of cement is not a linear relationship, as only comparatively modest strength gains occur as the percentage of cement is increased from five to twenty percent. Inherent variability in constituent materials and questionable homogeneity of the mixed materials contribute to some variability in the compressive strength results. However, the coefficients of variation for the three-specimen sets were generally within 10 percent and rarely exceeded 15 percent. In all cases, dramatic compressive strength gains came with very modest (between 5 and 10 percent) additions of cement.

The modulus of elasticity of the test specimens was computed based on results from the compression testing. These results are shown in Table 5. Because cube specimens were used and the strain was calculated from displacement of the loading platen, these stiffness results should be considered estimates. However, they can be used to observe the relative effect resulting from the addition of Portland cement. The addition of cement clearly increases the stiffness, with values of two to three times those for specimens made with SDA material as the only binding agent. However, as with the compressive strength results, there do not appear to be coherent trends in the data relating increased percentages of cement to further increases in stiffness. Essentially, the addition of Portland cement has a significant stiffening effect without respect to the amount of cement.

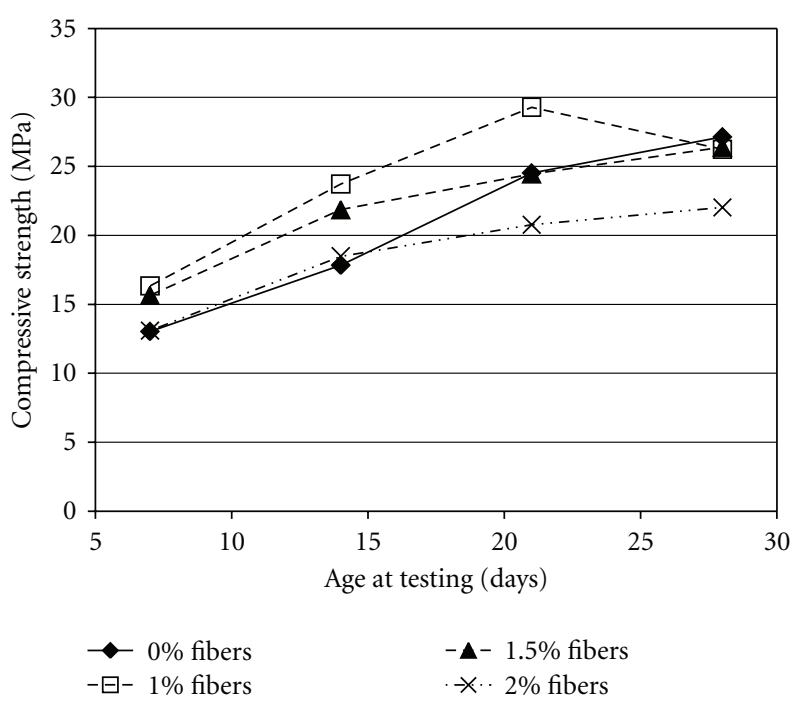

FIGURE 6: Effect of increasing percentages of recycled polymer fiber on the compressive strength of a mortar with ten percent type I/II cement.

TABLE 6: Modulus of elasticity for different percentages of fibers for a mortar made with $10 \%$ type I/II cement ( $\mathrm{MPa})$.

\begin{tabular}{lllll}
\hline \multicolumn{5}{c}{ \% Fibers } \\
Days & $0.0 \%$ & $1.0 \%$ & $1.5 \%$ & $2.0 \%$ \\
\hline 7 & 1666 & 2034 & 1724 & 1839 \\
14 & 2176 & 2468 & 2804 & 2237 \\
21 & 2612 & 2969 & 2596 & 2815 \\
28 & 3172 & 2697 & 2739 & 2861 \\
\hline
\end{tabular}

The effect of polymer fibers on the compressive strength was also considered with the addition of cement. Mortars were prepared with ten percent Type I/II cement and varying fiber contents. Figure 6 shows the results of different fiber contents on the compressive strength over the full testing period. At early ages, it appears that the addition of some fibers is helpful, but over time the strength benefit of the fibers is lost. Furthermore, there appears to be an optimal fiber fraction around 1 percent. The mixtures with 1 percent fibers (by weight) are stronger than the mixtures with 1.5 percent fibers at most ages, and both outperform the mixtures with 2 percent fibers. This result is consistent with the SDA paste results where the addition of 1 percent fibers clearly improved the compressive strength, and 2 percent 
TABLE 7: Modulus of rupture results for different types of cement, testing ages and percents of cement added (MPa).

\begin{tabular}{lccccccccc}
\hline & & \multicolumn{3}{c}{ Type I cement (Sets 2F-2I) } & \multicolumn{4}{c}{ Type III cement (Sets 2B-2E) } \\
Days & $0 \%$ & $5 \%$ & $10 \%$ & $15 \%$ & $20 \%$ & $5 \%$ & $10 \%$ & $15 \%$ & $20 \%$ \\
\hline 14 & 1.19 & 3.27 & 2.61 & 3.74 & 5.24 & 2.38 & 3.14 & 3.28 & 3.99 \\
28 & 1.54 & 3.05 & 3.11 & 4.85 & 6.44 & 2.58 & 3.74 & 3.34 & 4.21 \\
\hline
\end{tabular}

fiber addition had a detrimental effect. Results indicating the effect of fiber addition on the modulus of elasticity are shown in Table 6 and show that the addition of fibers to a mixture already containing cement is of little benefit to stiffness. There may be some mild advantage to fiber addition at early ages, but by 28 days the stiffness of specimens with fibers was less than that of the specimens without fibers.

Given the mechanics of failure of a brittle material in compression (shear failure along 45-degree planes and splitting along the axis of loading), the addition of reinforcing fibers to a stiff and brittle matrix may not have a significant impact on compressive strength or stiffness. Thus, the strengthening observed in the SDA paste specimens is likely the result of the weaker and less stiff matrix being reinforced by fibers that are relatively stiffer and thus able to reinforce the matrix prior to cracking. Once the matrix itself is stronger and stiffer, as is the case in the mortars with added cement, fibers can have a detrimental effect (due perhaps to a loss in workability) until cracking has occurred, and the fibers deform sufficiently to carry significant loads. These results are consistent with the highly variable results for fiber-reinforced concrete reported by other authors and summarized by Johnston [11]. Qualitatively, the mortar cubes with fibers behaved similarly to the neat spray dryer ash cubes (shown in Figure 3), remaining intact even after losing their load-carrying capacity.

Flexural testing was conducted at 14 and 28 days for mortar specimens with the addition of both cement and fibers. Table 7 presents the moduli of rupture (MOR) from these tests. The addition of cement appears to increase the flexural strength, although not to the degree witnessed for the compressive strength. The addition of 5 percent Type I/II cement increased the MOR by a factor of 1.98 at 28 days, and the addition of 5 percent Type III cement increased the MOR by a factor of 1.68 at 28 days compared to the cement-free mortar specimens. Figure 7 compares the effect of different percentages of the two different types of cement on the MOR achieved at 28 days. This plot shows that adding increasing percentages of Type I/II cement continues to increase the MOR; however, the continued addition of Type III cement beyond 10 percent appears to offer little benefit.

The addition of fibers to concrete typically provides added capacity to the regions of the test specimen in tension, potentially increasing the overall flexural strength of the specimen. Figure 8 shows the effect of different fiber contents on the flexural strength at both 14 and 28 days. The addition of 1 percent fibers clearly improves the MOR compared to specimens without any fibers at all, with increases of between 10 and 30 percent. However, similar to the results observed in compression, the addition of larger percentages of fibers

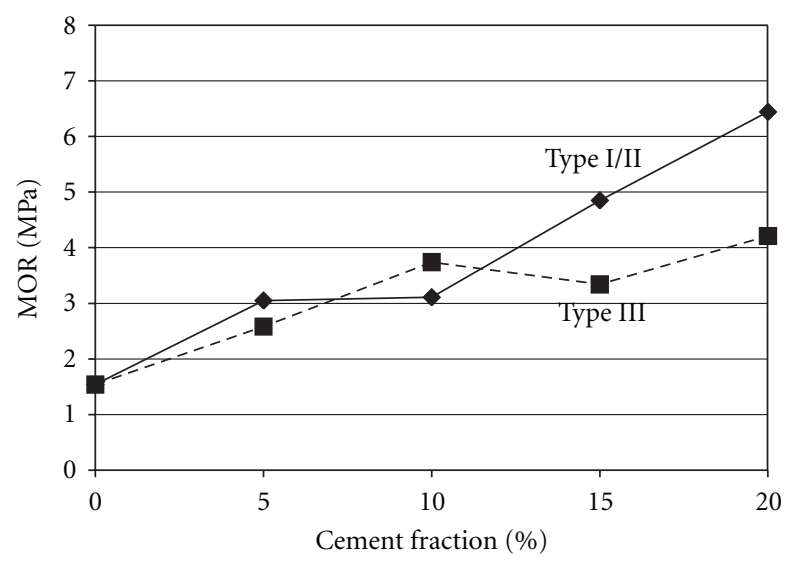

Figure 7: Comparison of MOR at 28 days for mixtures with type I/II and type III cement.

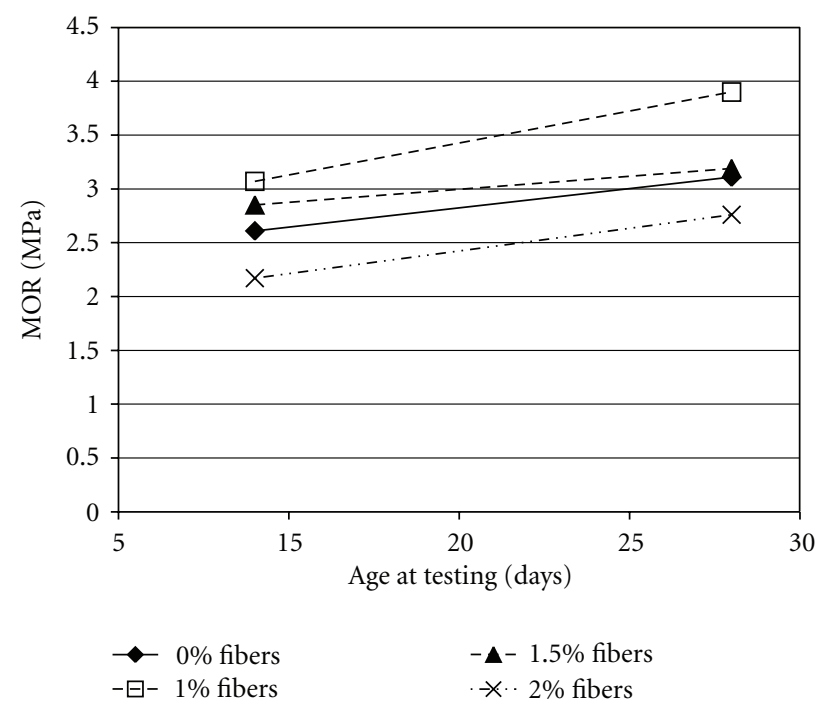

FIGURE 8: Effect of increasing percentages of recycled polymer fiber on the MOR of a mortar with ten percent type I/II cement.

was not beneficial. The mixture with 1.5 percent fibers had an average MOR approximately equal to the mixture with no fibers, and the mixture with 2 percent fibers actually had a lower MOR than the mixture without fibers. Thus, an optimal fiber content for both flexure and compression exists around 1 percent by weight for these particular materials.

Overall, the mixtures tested with additions of both cement and tire fiber showed significant promise as a potential engineering material. The strengths and stiffnesses showed significant improvement with as little as 5 percent addition 
of Portland cement and approximately 1 percent of fibers. Both Type I/II and Type III cements were found to be effective, with Type III cement increasing early strengths, while Type I/II cement produced higher later strengths. In terms of aesthetics and workability, the addition of the cement also eliminated concerns about the chalky finish associated with the SDA-only mixtures. The addition of cement also improved the workability of the pure spray dryer ash mortar, as the spray dryer ash-only mixtures tended to be sticky which made the finishing difficult.

\section{Summary and Conclusions}

Two phases of testing were used to investigate the use of spray dryer ash as a cementitious material for engineering use. Spray dryer ash alone mixed with water was found to be too weak in compression to offer benefits as a practical engineering material even for moderately structural components such as roof tiles. The addition of recycled polymer fibers increased the strength by a significant amount (10-50 percent), but the resulting strengths were still quite low. Other properties, such as a chalky finish, also indicated that spray dryer ash alone was not suitable as a matrix for most structural engineering applications.

Improvements were found in the properties of sanded mortars through the addition of small amounts of Portland cement to the ash-tire fiber mixture. Compressive strengths at the low end of the range typically considered for conventional concrete $(27 \mathrm{MPa})$ were achieved with only $5 \%$ additions of Portland cement. Recycled polymer fibers were shown to benefit the compressive and flexural strengths at additions of around 1 percent by weight, while greater fiber fractions had a limited or detrimental impact on strengths. The fibers were very effective at preventing spalling and loss of material due to fracture and contributed to increased toughness and ductility. This attribute may be desirable for certain applications.

This preliminary testing has been conducted on mortars, and thus, testing of concretes with large aggregate is a necessary next step. If structural applications are to be pursued, these practical applications will also require testing to ensure the durability of the product and its compatibility with reinforcing bar from both a bonding and corrosion perspective. The results of the study presented herein indicate a high potential for useful application of this material and provide justification for further studies focusing on specific applications. Significant waste diversion through beneficial use of spray dryer ash appears to be a viable objective.

\section{Acknowledgements}

The authors gratefully acknowledge the Colorado Commission on Higher Education (CCHE) for support of this research through contract no. 07 GAA 00018. The spray dyer ash and recycled tire fibers were provided for this research by the Platte River Power Authority and Jai Tire, respectively. The authors also acknowledge the assistance of the students who worked on this project including Jeff Eulberg, Stephanie Thomas, Balaji Mahalingam, Fredrick Busch, and Karthik Rechan.

\section{References}

[1] ACI Committee 232.2, Use of Fly Ash in Concrete, American Concrete Institute, Farmington Hills, Mich, USA, 2003.

[2] EPRI, "A review of literature related to the use of spray dryer absorber material-production, characterization, utilization applications, barriers, and recommendations," TR1014915, Electric Power Research Institute, September 2007.

[3] ACAA, "Coal combustion product (CCP) production and use survey," American Coal Ash Association. Aurora, Colo, USA, 2008, http://www.acaa-usa.org/.

[4] ASTM International, C33 Standard Specification for Concrete Aggregates, ASTM International, West Conshohocken, Pa, USA, 2008.

[5] ASTM International, C618 Standard Specification for Coal Fly Ash and Raw or Calcined Natural Pozzolan for Use in Concrete, ASTM International, West Conshohocken, Pa, USA, 2005.

[6] A. Bilodeau and V. M. Malhotra, "High-volume fly ash system: concrete solution for sustainable development," ACI Structural Journal, vol. 97, no. 1, pp. 41-48, 2000.

[7] ASTM International, C109 Standard Test Method for Compressive Strength of Hydraulic Cement Mortars, ASTM International, West Conshohocken, Pa, USA, 2008.

[8] ASTM International, C78 Standard Test Method for Flexural Strength of Concrete, ASTM International, West Conshohocken, Pa, USA, 2008.

[9] ASTM International, C305 Standard Practice for Mechanical Mixing of Hydraulic Cement Pastes and Mortars of Plastic Consistency, ASTM International, West Conshohocken, Pa, USA, 2008.

[10] J. Little, "Spray dryer ash finds a market," Ash at Work, no. 1, pp. 10-11, 2008.

[11] C. D. Johnston, Fiber-Reinforced Cements and Concretes, Gordon and Breach Science Publishers, Amsterdam, The Netherlands, 2001. 

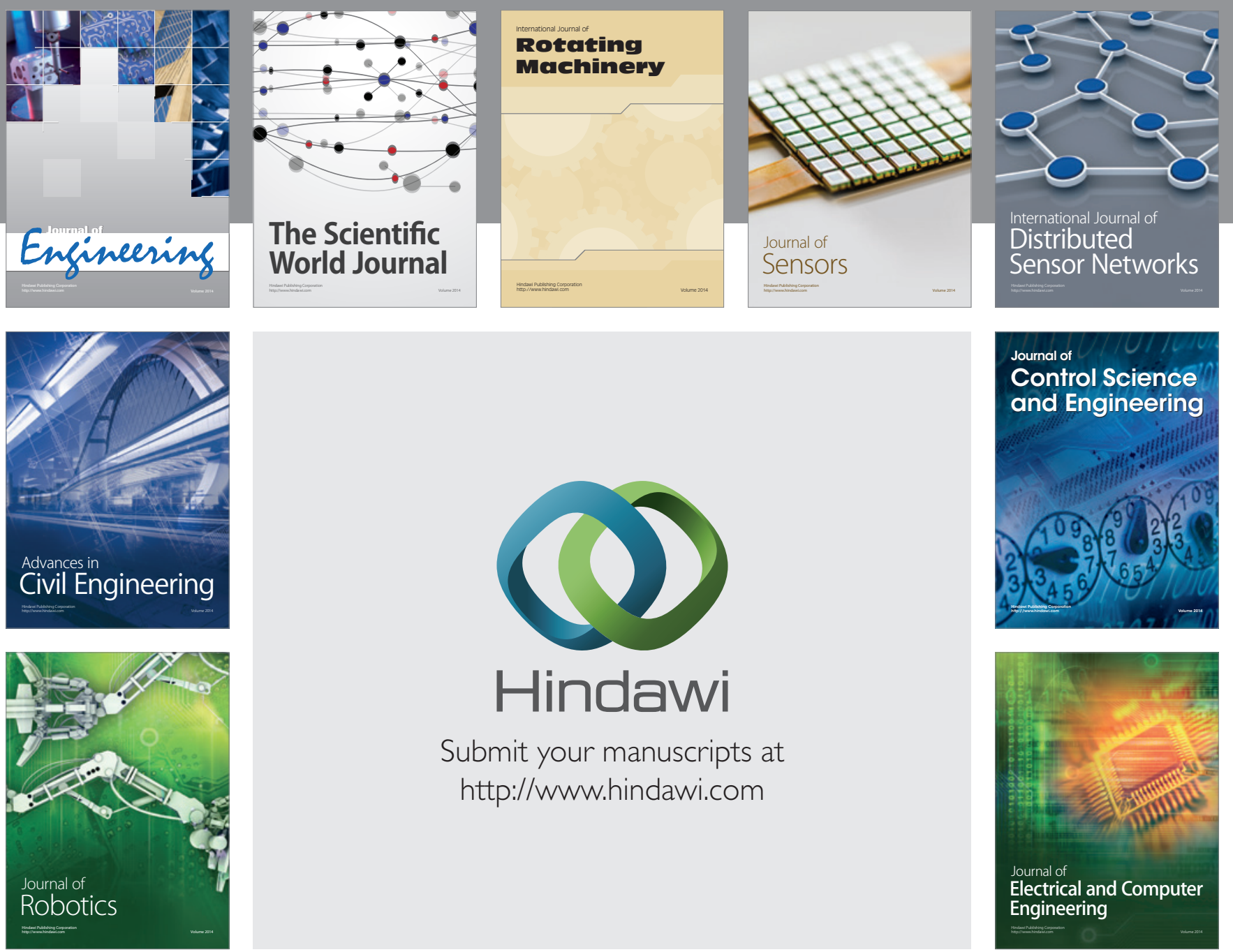

Submit your manuscripts at

http://www.hindawi.com
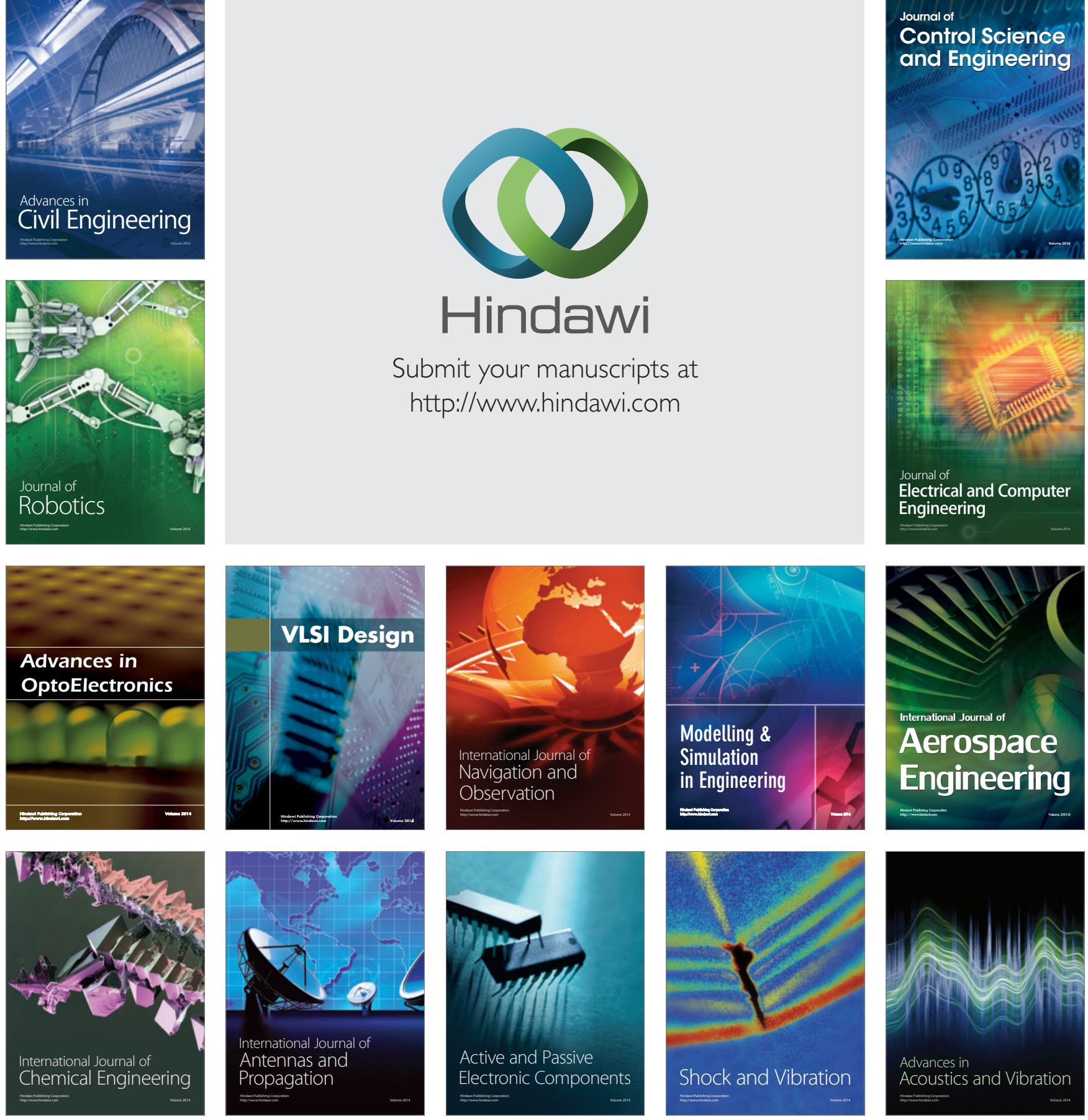